\title{
GOVERNANCE STRUCTURES IN WHEAT SUPPLY CHAINS AND THEIR IMPACTS ON PRODUCTIVITY AND PROFITABILITY OF WHEAT PRODUCERS IN ETHIOPIA
}

\author{
Zewdie Habte Shikur ${ }^{\bowtie}$ \\ Wolaita Sodo University, Ethiopia
}

\begin{abstract}
This study aims to supplement the literature on the factors affecting wheat producer productivity and profitability by focusing on the role of governance structures and asymmetric information - an issue that is rarely discussed in developing countries. The study thoroughly explores the effect of governance structures and asymmetric information to model a hypothesis for Ethiopia. The study area enables an exemplary case study as it is one of the top wheat-producing areas in both Ethiopia and all of Africa. The study area has also been registered as a wheat belt region in Sub-Saharan Africa. This study used personal interviews to collect primary data from actors. Mixed sampling techniques (i.e., random, census, and purposive) were used to select sampling units. Multiple linear regression models were used to analyse the data. The results show that governance structures, Farm-gate transactions, and asymmetric information have a significant effect on wheat productivity and profitability. Asymmetric information significantly reduces the profit and yield of wheat producers. The study implies that the government should apply a policy related to institutional arrangements to enhance productivity and profitability in wheat supply chains.
\end{abstract}

Keywords: governance structures, Farm-gate transactions, asymmetric information, wheat supply chain, wheat productivity, profitability

\section{INTRODUCTION}

Contractual arrangement is one of the governance structures that integrate farmers into modern food supply chains through a formal and informal contractual relationship (Minot and Roy, 2007; Narayanan, 2012). Governance structures decrease the cost of transactions and reduce coordination failure (information search, incomplete information, asymmetric information while searching for products in the market, input and credit supply constraints, etc.). Governance structures often build formal or informal binding agreements about expected quantity, quality and price in advance (Barrett et al., 2012). Contractual relationships arrange inputs, credit, and extension services for farmers, and reduce the risk for actors in terms of production, price, and quality (Herath and Weersink, 2009; Shikur et al., 2020). Contracts can also be used as a tool to share yield and price risks between the principal and agents (Barrett et al., 2012). Contractual arrangements enhance the productivity and food security of actors in general and can raise the prices charged by wheat farmers (Jia and Bijman, 2013; Shikur et al., 2020). However, the effect of institutional arrangements on actors' welfare is a controversial issue among scholars (e.g., Little and Watts, 1994; Key and Runsten, 1999; Oya, 2012). From the political economy point of view, contractual

\footnotetext{
$\bowtie$ Zewdie Habte Shikur, Department of Agricultural Economics, Wolaita Sodo University, Ethiopia, e-mail: zewde91@gmail.com, https://orcid.org/0000-0002-5762-8603
} 
arrangements create unequal bargaining power relations (Wilson, 1986). Some scholars argue that contractual arrangements decrease the farmers' power while increasing their production risk. Others claim that contractual arrangements are one of the mechanisms to tackle coordination failures (e.g., Key and Runsten, 1999; Kirsten and Sartorius, 2002; Minten et al., 2009). More explicitly, this literature focuses on the effect of institutional arrangements, dealing with coordination failure resulting from uncertainty, risk, and market imperfections. This study focuses on investigating the effect of institutional arrangements on the productivity and profitability of wheat producers in the wheat supply chain. Existing empirical findings do not deliver adequate evidence on the effects of institutional arrangements on productivity and profitability in developing countries. Therefore, empirical evidence is required to design and facilitate contractual arrangements that could improve the productivity and profitability of actors in the wheat supply chain (Brousseau, 2008). Quantitative and qualitative analyses of the problem have been a vibrant area of research that would provide a good exemplary case study and new insights. This study adds to the current knowledge in two aspects. First, it distinguishes problems of the existing contractual arrangements and argues how to address them to assist the needs of actors in the wheat supply chain. Second, it employs a qualitative research approach, which is underutilised in agricultural supply chain studies (Locke and Lloyd-Sherlock, 2011). The objectives of this study are to study the effects of the transaction and behavioural attributes on the actors' profitability and wheat yields in wheat supply chains and identify the determinants of farmer profitability and wheat yield based on the example of a case study on a sample of Ethiopian farms. The study contributes to the existing literature by enhancing the overall understanding of the current institutional arrangements in the wheat supply chain. It provides a new perspective, particularly in the case of Ethiopia's wheat supply chain, on the effect of governance structures on producer wheat productivity and profitability. The study's background and motivations are outlined in Section 1 while the literature is presented in Section 2. Section 3 contains a description of sampling techniques and methods of data collection and analysis, whereas the results are discussed in Section 4. Lastly, the study concludes with the findings and policy implications.

\section{LITERATURE REVIEW}

This literature review aims to provide an understanding of the institutional arrangements that could boost productivity and profitability by reducing the actor risk and uncertainty in food supply chains. The study does intend to provide a full literature review of the institutional arrangements and coordination failure effects of agricultural productivity and profitability. Coordination failures and transaction costs in the supply chain could be used to explain a specific form of governance structures.

New Institutional Economics (NIE) deals with the most favourable governance structures. NIE can be divided into two branches, i.e., transaction cost economics and agency theory. Transaction cost economics focuses on three types of institutional arrangements - the spot market, hybrid, and hierarchy (Williamson, 1985); a price mechanism coordinates transactions only in the spot market, whereas one entity controls all the production and marketing stages of a value chain in vertical integration (Hobbs, 1996). Institutional arrangements link the various supply chain actors (i.e., trust, contracts, degree of vertical and horizontal coordination and integration) (Merlin, 2005), secure contractual relationships, facilitate coordination, organise transactions, and settle disagreements in agricultural food chains (Ménard, 2004).

The food supply chain is known for high uncertainty and risk because of product perishability. Food transactions in the supply chain suffer from frequent market failures in developing countries, with actors are facing further risk and uncertainty as a result (Poole et al., 1998; Shikur et al., 2020). Many scholars argue that governance structures play a central role in determining actors' incentives (costs and benefits) in food supply chains (e.g., Wolf et al., 2001; Dekker, 2003; Abebe et al., 2013).

Scholars explain contract problems using a principal-agent framework. Contractual arrangements are formulated to provide sufficient incentives to match the objectives of the agent with those of the principal. A principal is a party who models and recommends the contract; an agent is a party, who either accepts or rejects the contract suggested by the principal. Agency theory is employed to explain and govern the rights and duties of a principal and agent to the contract.

Asymmetric information is assumed to be one of the causes of agency problems. Information asymmetry 
occurs when agents have more information about the price and quality of inputs and products than the principal. Information asymmetry generates moral hazard and adverse selection problems. A moral hazard exists between the two parties when the agent has more knowledge about his actions than the contractor (principal). For example, under the conditions of moral hazard, the principal cannot observe many of the agent's actions, and in terms of the agent undertaking practices to assure high yield and quality, the principal must "take the agent's word for it". The contract theory in literature designs and suggests solutions to moral hazard problems. Adverse section problems occur between two parties when the agents have more information about the method of production, prices, quality and their behaviour than the principal (Akerlof, 1970). Contractual arrangements are designed to tackle disagreement or conflicts of interest between two parties. For example, the principal may want the agent to supply new, quality agricultural inputs or products, but this largely increases the costs of production for the agent. The agent wants to reduce costs of production and transaction to maximise his profit (Holmstrom and Milgrom, 1994).

Contract farming functions as an intermediate governance mode, which falls somewhere between spot market and vertical integration (Key and Rusten, 1999). Agricultural contracts play a central role in reducing transaction and coordination costs that lead to higher profitability and productivity (Bogetoft and Olesen, 2002). Contractual arrangements minimise production risks due to coordination failures in input and output markets (e.g., unavailability of fertilisers at crucial moments in the plant growth cycle). Additionally, the contractual arrangements reduce input quality uncertainty, and output and input price uncertainties due to opportunistic behaviour and information asymmetries (Smale et al., 1994; Shikur et al., 2020). Ineffective institutional arrangements adversely affect the producers' profit and productivity. In an institutional arrangement scheme, the main contract design problem of the producers relate to the quality and price of the product; the sufficiency of supply; the necessary inputs; and the coordination of production, harvesting and delivery (Key and Runsten, 1999). The firm's solution to this problem is often to establish profit-maximising contract terms with the assumption that the farmer will accept and honour them. Although earlier literature has widely studied the effect of contracting on farm income in different countries (e.g., Eaton and Shepherd, 2001; Girma and Gardebroek, 2015), empirical studies examining the effect of governance structures on yield and profit in wheat supply chains are still rare in Ethiopia. Therefore, this study describes the effects of the transaction and behavioural attributes on the actors' profitability and wheat yields in wheat supply chains and identifies the determinants of farmer profitability and wheat yield in Ethiopia.

\section{METHODOLOGY}

\section{Overview of the study area}

The agriculture sector contributes about $36 \%$ to Ethiopia's GDP and provides a livelihood for about $83.4 \%$ of its people, accounting for about $80 \%$ of the total value of its exports and nearly $75 \%$ of the raw material requirements. In Ethiopia, the agricultural sector provides food and raw material supplies for agro-processing industries, as well as better jobs for impoverished people, and income. To study the determinants of the farmer profitability and wheat yield based on the example of the case study realised on a sample of Ethiopian farms, the Arsi and East Shewa zones in the Oromia region were chosen for this study; this is also because wheat accounts for about $20 \%$ of the total African grain production (FAOSTAT, 2018) and about $14 \%$ of the total calories consumed by the Ethiopian people (FAO, 2014) and provides a livelihood for more than $30 \%$ of all smallholder farmers in Ethiopia. The wheat industry is the source of income and food for both urban and rural people. It also significantly contributes to animal feed (Habte et al., 2020). The study area enables an exemplary case study as it is one of the top wheat-producing areas in Ethiopia and all of Africa. The study area has been registered as a wheat belt region in Sub-Saharan Africa. Wheat production is a staple of the livelihood of wheatproducing farmers and a source of raw material for flour and food factories. Wheat producers produce wheat and sell their produce to downstream actors in the wheat supply chain. They also purchase inputs and industrial products from traders. Flour and food industry entities purchase wheat from the traders and sell their products to downstream actors and end-users. Wheat produced by the wheat producers goes through different sectors with significant value addition. Costs are incurred at the different stages of the value chain, which is at a different production level for inputs, as well as at the distribution and marketing level for transportation, storage and 
transactions. However, wheat supply chains suffer from weak market coordination. Actors in the supply chains are linked by asymmetric information. Framers in Ethiopia have not been benefiting from the existing wheat market system due to the influence that traders have in setting prices. Farmers are subject to high input risks among actors in wheat supply chains due to imperfect markets and poor market linkages (Shikur et al., 2020).

Transaction attributes are described using frequency, uncertainty, and asset specificity. According to the surveys, the uncertainty of input quality is high due to information asymmetry in the study areas. Uncertainty in the study areas increase transaction risks and adversely affect actors' incentives. The level of transaction costs increases with uncertainty (increase) and frequency (decrease), which supports long-established knowledge (Williamson, 1999). The surveys indicate that the pesticide and herbicide input quality and price uncertainties decrease wheat producers' wheat yield and profit. Frequency affects information flow, transaction costs, cooperation, coordination, and short-term credit (Shikur et al., 2020). Less frequent transactions can increase the profitability of opportunistic behaviour and exploiting information asymmetries (Hobbs, 1996). Input markets are characterised by high information asymmetry, lack of means of quality control and no other bonds existing between the actors before or after the transactions, which is consistent with the findings of Dwyer et al. (1987). Input retailers have more information about their own action than farmers.

\section{Sampling method}

Surveys were carried out in major wheat-producing zones. In the first and second stage, the survey focused exclusively on area selection, with 3 districts and 6 villages randomly selected from the Arsi and East Show zones, respectively. In the third stage of the research, 220 wheat producers were randomly selected from selected villages and interviewed in the major wheat-producing villages. The 220 respondents were determined based on 10 or more times explanatory variables in the specified model that has been suggested by several econometricians (Edriss, 2013).

The spot and non-spot markets were purposively selected from 3 randomly selected major wheat-producing districts. Criteria for the selection of these targeted markets included the physical proximity of wheat producers to the markets in these districts. Census surveys were conducted to collect research data from wholesalers in 4 selected markets. 20 retail input suppliers and 21 wheat wholesalers at the spot markets, as well as 29 wheat wholesalers at the non-spot markets, were selected using census and purposive sampling methods. A census survey was conducted to collect research data from wheat processors in the major wheat-producing districts. The total sample size of wheat processors was 30 in the major wheat-producing districts. This study purposively chose 13 cooperatives (i.e., a total of 26 experts from 13 cooperatives) to collect data in these 3 districts.

\section{Data collection method}

This study used a personal interview survey to collect the research data. Before final data collection, a preliminary survey was carried out to introduce appropriate modifications to the interview schedules and informal group discussion. The data was collected in 2016. The different interview schedules were prepared to collect data from different actors in the wheat supply chain. The interview schedules were employed to collect data from the farmers. Group discussion and key informant interviews were also used to collect data from farmers. Wholesalers at the spot and non-spot markets and input suppliers at small retail shops and spot markets were visited and interviewed at different times of the day. Wholesale input suppliers were interviewed in Addis Ababa. Flour and food industries were visited and interviewed using interview schedules in each district. In addition, traders and wheat processors in the towns of Adama, Assela, and Bishoftu, as well as Addis Ababa, were visited and interviewed. Agricultural cooperatives were visited to collect research data.

\section{Data analysis}

The empirical analysis was based on 220 wheat producers. The regression analyses are limited to wheat producers, as there were few other actors in wheat supply chains. The data were analysed using multiple linear regression models. Multiple linear regression models were used to assess the effects of institutional arrangements on the yield and profit of wheat producers. The coefficients of the Ordinary Least Square (OLS) are presented in Tables $1 \& 2$. Different diagnostic tests, such as multicollinearity and normality tests, were performed to check the healthiness of the model (Tables 3 and 4). The result of the Breush-Pagan-Godfrey test indicates that the residuals are not heteroscedastic (Observed 
$\mathrm{R}$-square $=4.45, \mathrm{P}=0.67$ for wheat yield, Observed $\mathrm{R}$ square $=5.45, \mathrm{p}=0.083$ for profit). The specification of the multiple linear regression models is presented below.

$$
Y_{\mathrm{i}}=\beta_{0}+\beta_{1} x_{1}+\beta_{2} x_{2}+\beta_{3} x_{3}+\ldots+\beta_{\mathrm{k}} x_{\mathrm{k}}+\varepsilon_{\mathrm{i}}
$$

where:

$Y_{\mathrm{i}}-$ is dependent variables such as wheat yield and profit of wheat producer;

$\beta_{0}-$ is the intercept term of the model;

$\varepsilon_{\mathrm{i}}$ - is the disturbance term of the model;

$\beta_{1}, \beta_{2}, \beta_{3}, \ldots, \beta_{\mathrm{k}}$ - are vectors of parameters to be estimated by the model and;

$x_{1}, x_{2}, x_{3}, \ldots, x_{\mathrm{k}}-$ are independent variables in the model.

\section{RESULTS AND DISCUSSIONS}

\section{Transaction attributes and asymmetric information}

According to the survey result, around $90 \%$ of wheat transactions is concluded between wheat wholesalers and wheat processors based on trust. This maintains stronger cooperation, coordination, and short-term credit. It also extends the length of their relationships and brings further wheat transactions while maintaining a more frequent wheat price information flow between and reducing the costs of searching for partners and wheat price information. Neither actor wants to damage their reputation and long-term business relations as these affect their future incentives and quantity of wheat supply. If wholesalers sell the lowest quality wheat to wheat processors, they damage their long-term business relations. Wholesalers also purchase wheat from their customers without checking its quality and visit their customers during wedding and funeral ceremonies to maintain business relationships.

According to the surveys, input quality and price uncertainties are rampant in the spot input markets. Uncertainty concerning the quality of pesticides and herbicides constitutes a challenge for wheat producers in the spot input markets. Wheat producers with high input quality uncertainty obtained lower yield and profit due to the use of lower quality inputs. The finding supports claims that farming transactions significantly suffer due to the unverified input quality (Wolf et al., 2001). As a result, about $30 \%$ of wheat producers used low-quality pesticides and herbicides, whereas their wheat yield (on average, 17 quintals per ha) was about $57 \%$ lower than what could be obtained with higher quality inputs. This result validates the claim that an ineffective institution enables the existence of low-quality inputs in the markets that lead to low wheat productivity and high production cost per unit, which was put forth by North (1990). The study found the uncertainty and risk in input markets that face wheat producers. Uncertainty of input quality reduces both yield and profit (Williamson, 1996).

Farmers in the study areas could not understand the opportunistic behaviour of input sellers, and when purchasing inputs, they had to rely on the retailers' claims assuring them that the inputs are of high quality and will bring them high yield and profit. Retailers have more knowledge about the brand, trademark, quality, and price of inputs than farmers. This adverse selection reduces both the quality and quantity of inputs that would lead to coordination failure as well as low productivity and profitability (Akerlof, 1970). Farmers lack information to appropriately assess inputs quality and determine the price that would sufficiently reflect the costs of input storage, transport, labour and transaction borne by the suppliers. As such, farmers may overpay for pesticides and herbicides. The fear of over-paying for and uncertainty in terms of input quality causes farmers to reduce the number of inputs purchased at marketplaces. The findings support the works of Hueth et al. (1999), Kherallah and Kirsten (2002), Shikur et al. (2020), which state that information asymmetry on herbicide and pesticide quality leads to high transaction risks and low productivity and profit in the study areas.

\section{Governance structures}

Four types of governance structures exist in the study area, including the spot market, relational contracts, Farm-gate transactions and cooperative governance structures. The study found that the profit and yield of wheat producers varied across governance structures. Each governance structure is briefly discussed in the next sections.

Verbal agreements on wheat supply concluded by WVC actors are called rational contracts. Before the wheat transaction, the wheat producers negotiated with two or more wholesalers on the price of wheat via phone or in face-to-face conversations at non-spot markets. Wheat producers supply wheat to wholesalers regardless of delivery time and frequency. But relational 
contracts between actors did not exist in input markets which were highly characterised by opportunistic behaviour. The absence of a rational contract decreases the yield and profit of wheat producers by increasing input quality uncertainty and the price of agricultural inputs. Consequently, input suppliers exploited this information asymmetry and requested wheat producers to pay a higher price for inputs of inferior input. The verbal binding agreements between the wholesalers and wheat processors are built based on trust and long-term business relations. Wholesalers supply wheat to wheat processors per the latter's quantity demand. Relational contracts with a price premium for wheat were practised by $63 \%$ of wheat processors to ensure a reliable wheat supply. About $75 \%$ of wholesalers had two or more wheat processors as customers (Shikur et al., 2020). These contractual arrangements increase the profit of both wholesalers and wheat processors by reducing transaction costs.

Farm-gate transactions enable wheat producers to earn the highest profit and reduce costs of transportation compared to other governance structures. Farmgate transactions take place at farmers' fields. Buyers come to a farmer's field with trucks and negotiate the price of wheat with producers. Buyers cover the costs of physical marketing such as transport, loading and unloading costs. The wheat producers' bargaining power is the highest in the Farm-gate transactions and the lowest under spot market transactions.

Cooperative is one of the hybrid governance structures that combine both backward and forward activities for improved benefits (Hennessy, 1996). Theories argue that collective action increases economies of scale and bargaining power and reduces transaction and physical marketing costs. Collective action is one of the strategies to obtain gains from input and output markets and provide mutual protection against risk and uncertainty. It is also a strategy that can be used to overcome coordination failures because of asymmetric information, incomplete information, and opportunistic behaviour (Menar, 2007; Shikur et al., 2020). While farmers take collective action to reduce information asymmetries and transaction costs and create better input and output markets in the study areas, they are unsuccessful in doing so, likely because of self-serving individuals (Alemu et al., 2016).

The committee and managers will not act to attain members' common goals. Self-serving managers of cooperatives adopt strategies to benefit themselves at the cost of wheat producers. They also work with traders to reduce the quantity of pesticide and herbicide supplies in cooperative stores. Traders bribe cooperative managers and committees to make above-average profits at the cost of farmers. The cooperatives are not unconditionally accountable for the supply of the required quantity of high-quality inputs, such as chemicals, fertilisers, and funding (Habte et al., 2020). They create shortages of pesticides and herbicides in demand at cooperative stores, which allows traders to charge higher prices for lower quality inputs (Smale et al., 1994; Shikur et al., 2020). This strategy leads to a lower yield and profit for wheat producers. It also affects the welfare of both producers and consumers by reducing yield and profit and increasing the cost of wheat production. This implies that members who cannot tackle collective action challenges need to have externally enforced rules to achieve their long-term interests.

\section{Model results}

The study estimates the effects of governance structures on wheat yield and profit. Table 1 shows the influence of governance structures on wheat yield and profit. The estimate shown in Table 1 reports the coefficients of multiple regression models. Education, Farm-gate transactions, and fertiliser use have a significant and positive effect on wheat yield. Governance structures do not significantly increase wheat yield because contractual arrangements do not include input supply and in-kind credit exchanges between producers and wholesalers or wheat processors. The effect of asymmetric information on wheat yield is significant, but the sign is negative. For wheat producers, experiencing asymmetric information is associated with an average wheat yield decrease of 0.40 quintal compared to producers not experiencing asymmetric information, with other variables remaining constant. This piece of evidence suggests wheat yield is low due to asymmetric information. Low wheat yield is also caused by the absence of certifying agencies in input markets that certify the quality of inputs. In general, the existence of asymmetric information decreases the productivity of wheat farming (Habte et al., 2020).

The regression analysis shows the existence of a positive and significant relationship between the Farm-gate transactions and wheat yield. Education significantly affects wheat yield. An increase in education by one grade leads to an average yield increase of 0.34 
Shikur, Z. H. (2021). Governance structures in wheat supply chains and their impacts on productivity and profitability of wheat producers in Ethiopia. J. Agribus. Rural Dev., 2(60), 203-212. http://dx.doi.org/10.17306/J.JARD.2021.01396

Table 1. The effect of governance structures on wheat yield

\begin{tabular}{lccc}
\hline \multicolumn{1}{c}{ Variables } & Coefficient & St. error & P-value \\
\hline Governance structures & 1.69 & 1.06 & 0.11 \\
Farm-gate transaction & $4.38^{* *}$ & 1.89 & 0.02 \\
Cooperative membership & 2.13 & 1.61 & 0.19 \\
Asymmetric information & $0.40^{* *}$ & 0.01 & 0.02 \\
Education & $0.34 * *$ & 0.15 & 0.04 \\
Farm size & -0.14 & 0.12 & 0.24 \\
Labour supply & -0.11 & 0.17 & 0.41 \\
Livestock number & 0.28 & 0.20 & 0.16 \\
Credit utilization & 2.07 & 1.40 & 0.14 \\
Fertiliser use & $0.22 * * *$ & 0.06 & 0.00 \\
Constant & -31.49 & 2.14 & 0.00 \\
Number of observations & 2020 & & \\
F(11, 207) & 6.65 & & 0.00 \\
R-square & 0.62 & & \\
Adjusted R-square & 0.60 & & \\
\hline
\end{tabular}

$* * *, * *$ and $*$ indicate significance at the $1 \%, 5 \%$ and $10 \%$ levels, respectively.

Source: survey data, 2016.

quintals. Increasing fertiliser use by 1 quintal engenders an increase in wheat yield by an average of 0.22 quintals, other factors held constant. A 1-hectare increase in the farm size engenders a decrease in wheat yield by an average of 0.14 quintals, with other variables held constant.

Governance structures, Farm-gate transaction, farm size, wheat yield and the average price of wheat significantly and positively determine the profitability of wheat producers. The positive sign of the governance structures coefficient implies that institutional arrangements would have a statistically significant effect on wheat producer profit. The result indicates that Farmgate transactions significantly increase the profitability of wheat producers (Table 2). Farm-gate transactions are found to be more appropriate for increasing farmer profitability because they decrease loading, unloading, and transportation costs. In this case, such costs are covered by wholesalers. Asymmetric information has a significant and negative effect on wheat producer profitability. This finding suggests that it could decrease farmer
Table 2. The effect of governance structures on farmers' profit

\begin{tabular}{lccc}
\hline \multicolumn{1}{c}{ Variables } & Coefficient & St. error & P-value \\
\hline Governance structures & $0.23^{* *}$ & 0.10 & 0.03 \\
Farm-gate transaction & $4.46^{* * *}$ & 0.92 & 0.00 \\
Power relation & -0.14 & 0.38 & 0.71 \\
Cooperative membership & 0.64 & 0.54 & 0.13 \\
Combine use & 0.03 & 0.02 & 0.12 \\
Asymmetric information & $-0.05^{* *}$ & 0.02 & 0.02 \\
Farm size & $0.45^{* *}$ & 0.18 & 0.02 \\
Wheat yield & $1.58^{* * *}$ & 0.18 & 0.00 \\
Average price of wheat & $0.43^{* * *}$ & 0.12 & 0.00 \\
Constant & -30.86 & 16.99 & 0.07 \\
Number of observations & 220 & & \\
F(6, 213) & 52.65 & & 0.00 \\
R-square & 0.59 & & \\
Adjusted R-square & 0.58 & & \\
\hline
\end{tabular}

$* * *, * *$ and $*$ indicate significance at the $1 \%, 5 \%$ and $10 \%$ levels, respectively.

Source: survey data, 2016.

Table 3. Multicollinearity test for explanatory variables used in multiple regression models

\begin{tabular}{lcc}
\hline \multicolumn{1}{c}{ Variables } & VIF & 1/VIF \\
\hline Governance structures & 5.21 & 0.19 \\
Farm-gate transaction & 4.32 & 0.23 \\
Cooperative membership & 2.53 & 0.40 \\
Asymmetric information & 4.87 & 0.20 \\
Education & 3.65 & 0.27 \\
Farm size & 3.42 & 0.29 \\
Labour supply & 1.98 & 0.50 \\
Livestock number & 1.33 & 0.75 \\
Credit use & 1.83 & 0.55 \\
Fertiliser use & 4.34 & 0.23 \\
Mean VIF & 3.14 & \\
\hline
\end{tabular}

Source: survey data, 2016. 
Table 4. Test statistics for normal distribution with Shapiro-Francia W test

\begin{tabular}{lcccl}
\hline Explanatory variables & $\mathrm{W}$ & $\mathrm{V}$ & Z-value & $\mathrm{P}>\mathrm{Z}$ \\
\hline Education & 0.96 & 0.68 & 0.62 & 0.73 \\
Livestock & 0.05 & 1.89 & 1.11 & 0.13 \\
Landholding size & $0.02^{\mathrm{s}}$ & 0.02 & 1.01 & 0.31 \\
Fertiliser used & 1.73 & 0.38 & 1.85 & 0.052 \\
Labor supply & 0.99 & 1.72 & 1.25 & 0.11 \\
\hline
\end{tabular}

$\mathrm{W}=$ Test statistic, $\mathrm{V}=$ Covariance matrix.

Source: survey data, 2015/2016.

profitability. The negative sign of the coefficient implies that coordination failure leads to low wheat yield and profitability due to the use of poor-quality inputs in the production process (Habte et al., 2020; Shikur et al., 2020). Coordination failures limit farmers' innovation and limit their profit from wheat production.

The wheat yield has a significant and positive effect on profitability at a $1 \%$ level of significance. A 1 quintal increase in yield improves wheat producer profitability by an average of 1.58 dollars, with all other variables remaining constant. A strong positive relationship with a $1 \%$ significance level also exists between the average wheat prices and profitability.

\section{CONCLUSIONS AND POLICY IMPLICATIONS}

The motivation of this paper is to understand the main reasons for the low wheat productivity and profitability. Since there is a lack of evidence on the effects of governance structures and asymmetric information on wheat productivity and wheat producer profitability in the wheat supply chains of developing countries, such supply chains suffer from asymmetric information, incomplete information, and opportunistic behaviour. These problems lead to low wheat productivity and low wheat supply in each supply chain node. The input market suffers from low input quality and price uncertainties due to opportunistic behaviour and information asymmetries.

Managers are bribed by traders, which affects the welfare of both producers and consumers by reducing yield and profit alike. This also creates unsold or surplus chemical input inventories at cooperative stores.
The strategy used by retailers leads to higher costs, as well as the presence of expired or adulterated pesticides and herbicides in the input markets. Members cannot overcome collective action problems and need to have externally enforced rules to achieve their own long-term interests. The findings from this study are highly relevant to policymakers and NGOs, which should motivate third parties and establish effective institutional arrangements that will ensure legal protection and fair conditions for actors in the wheat supply chain.

This study implies that governance structures affect food security and the welfare of producers as well as consumers. Governance structures have implications for the adoption of technologies. For instance, high profits motivate wheat producers to adopt wheat technologies that help them to increase wheat productivity and production. Increased productivity can also reduce wheat prices, which increases the purchasing power and real income of impoverished urban and rural consumers. The implications may extend to other sectors as well. For instance, such increased productivity would reduce the shortage of raw materials in the wheat processing industries. From a policy perspective, high wheat productivity secures adequate wheat and wheat product supplies.

To increase wheat yield and profit, governments should use such regulations as standardisation, certification, labelling and guaranteeing to reduce the opportunistic behaviours of the input sellers that arise from market failures. NGOs and GOs should work together to encourage and support private sectors and provide such services as laboratory tests and third-party certification to tackle the information asymmetry problems in input markets, weak pricing system, and risk and uncertainty regarding input quality. This allows governance structures to reduce wheat production costs while increasing actors' income and wheat productivity, greatly improving household food security as a result. The study also implies that the government should apply policies related to institutional arrangements to enhance productivity and profitability in wheat supply chains.

The main limitation is that the regression analyses were limited to wheat producers. Traders and wheat processors were unwilling to provide genuine information on their firms' productivity, costs, and profit for fear of income and sales taxes. The directions of further research should focus on the role of certification in productivity and profitability in the wheat supply chain. 


\section{REFERENCES}

Abebe, G.K., Bijman, J., Kemp, R., Omta, O., Tsegaye, A. (2013). Contract farming configuration: Smallholders'preferences for contract design attributes. Food Pol., 40, 14-24.

Akerlof, G. (1970). The market for lemons: Quality uncertainty and the market mechanism. Quart. J. Econ., 83(3), 488-500.

Alemu, A.E., Mathijs, E., Maertens, M., Deckers, J., Gegziabher, K., Bauer, H. Hiwot, K.G. (2012). Vertical coordination in the local food chains: Evidence from farmers' in Ethiopia. Int. J. Econ. Fin. Stud., 4(1), 11-20.

Alemu, A.E., Maertens, M., Deckers, J., Bauer, H., Mathijs, E. (2016). Impact of supply chain coordination on honey farmers' income in Tigray, Northern Ethiopia. Agric. Food Econ., 4(9), 1-21.

Barrett, C.B., Bachke, M.E., Bellemare, M.F., Michelson, H.C., Narayanan, S., Walker, T. F. (2012). Small-scale farmer participation in contract farming: Comparative evidence from five countries. World Dev., 40 (4), 715-730.

Bijman, J. (2008). Contract farming in developing countries: An overview, Working Paper. Wageningen: Department of Business Administration, Wageningen University.

Bogetoft, P., Olesen, H.B. (2002). Ten rules of thumb in contract design: Lessons from Danish agriculture. Eur. Rev. Agric. Econ., 29, 185-204.

Brousseau, E. (2008). From bilateral sets of incentives to the multi-level governance of relations. In: E. Brousseau, J.-M. Glachant (eds.), New Institutional Economics: A Guidebook (pp. 37-66). Cambridge: Cambridge University Press.

Cai, J., Setboonsarng, S., Dekker, H.C. (2003). Value chain analysis in inter-firm relationships: A field study. Manag. Account. Res., 14(1), 1-23.

DIIDRC (2011). Markets and rural poverty, upgrading in value chains. Earthscan: USA and Canada.

Dörr, A.C., Grote, U. (2009). The role of certification in the Brazilian fruit sector. Rev. Econ. Contem., 13(3), 539-571.

Dwyer, F.R., Schurr, P.H., Oh, S. (1987). Developing buyerseller relationships. J. Market., 51(2), 11-27.

Eaton, C., Shepherd, A.W. (2001). Contract farming: Partnerships for growth. FAO Agricultural services bulletin 145 . Rome: Food and Agriculture Organization.

Edriss, A.K. (2013). Pears of applied statistics for social sciences and professional consulting: Theory and STATA applications with real data. Canada: International i-Publishers.

FAO (2014). Food Balance Sheets. Rome: FAOSTAT.

FAOSTAT (2018). Faostat data, available at: http://faostat.fao. org/faostat (accessed July 2018).
Girma, J., Gardebroek, C. (2015). The impact of contracts on organic honey producers' incomes in southwestern Ethiopia. For. Pol. Econ., 50, 259-268.

Habte, Z., Legesse, B., Haji, J., Jaleta, M. (2020). Determinants of supply in the wheat value chain of Ethiopia. Eastern Africa Social Science Research Review, 36(1), 19-36.

Hennessy, D.A. (1996). Information asymmetry as a reason for food industry vertical integration. Am. J. Agric. Econ., 78, 1034-1043.

Herath, D., Weersink, A. (2009). From plantations to smallholder production: The role of policy in the reorganization of the Sri Lankan tea sector. World Development, 37 , 1759-1772.

Holmstrom, B., Milgrom, P. (1994). The firm as an incentive system. Am. Econ. Rev., 84(4), 972-991.

Hueth, B., Ligon, E., Wolf, S., WU, S. (1999). Incentive instruments in fruit and vegetable contracts: Input control, monitoring, measuring, and price risk. Rev. Agric. Econ., 21(2), 374-389.

Jia, X., Bijman, J. (2013). Contract farming: Synthetic themes for linking farmers to demanding markets. In: C.A.B. da Silva, M. Rankin (eds.), Contract farming for inclusive market access (pp. 21-38). Rome, Italy: Food and Agriculture Organization.

Key, N., Runsten, D. (1999). Contract farming, smallholders, and rural development in Latin America: the organization of agro-processing firms and the scale of out grower production. World Dev., 27, 381-401.

Kirsten, J., Sartorius, K. (2002). Linking agribusiness and small-scale farmers in developing countries: is there a new role for contract farming?. Dev. South. Afr., 19, 503-529.

Kherallah, M., Kirsten, J. (2002). The new institutional economics: Applications for agricultural policy research in developing countries. Agrekon, 41(2), 110-133.

Little, P.D., Watts, M.J. (1994). Living under contract, University of Wisconsin Press, Madison.

Locke, C., Lloyd-Sherlock, P. (2011). Qualitative life course methodologies: Critical reflections from development studies. Dev. Chan., 42(5), 1131-1152.

Menar, C. (2007). Cooperatives: Hierarchies or hybrids? In: K. Karantininis., J. Nilsson (eds.), Vertical Markets and Cooperative Hierarchies (pp. 1-17). Springer.

Merlin, B. (2005). The Value Chain Approach in Development Cooperation. (2nd ed.).

Ménard, C. (2004). The economics of hybrid organizations. J. Inst. Theor. Econ., 160(3), 345-376; https://doi.org/ $10.1628 / 0932456041960605$

Minot, N., Roy, D. (2007). Impact of high-value agriculture and modern marketing channels on poverty: An Analytical framework. IFPRI Food Policy Review. Washington, DC: International Food Policy Research Institute. 
Shikur, Z. H. (2021). Governance structures in wheat supply chains and their impacts on productivity and profitability of wheat producers in Ethiopia. J. Agribus. Rural Dev., 2(60), 203-212. http://dx.doi.org/10.17306/J.JARD.2021.01396

Minten, B., Randrianarison, L., Swinnen, J.F.M. (2009). Global retail chains and poor farmers: Evidence from Madagascar. World Dev., 37, 1728-1741.

Narayanan, S. (2012). Notional contracts: The moral economy of contract farming arrangements in India. Working Paper 2012-020. Mumbai: Indira Gandhi Institute of Development Research.

North, D. (1990). Institutions, institutional change and economic performance. Cambridge: Cambridge University Press.

Oya, C. (2012). Contract farming in Sub-Saharan Africa: A survey of approaches, debates and issues. J. Agrar. Chang., 12, 1-33.

Poole, N.D., Del Campo Gomis, F.J., Juliá Igual, J.F., Vidal Giménez, F. (1998). Formal contracts in fresh produce markets. Food Polic., 23, 131-142.

Smale, M., Just, R.E., Leathers, H.D. (1994). Land allocation in HYV adoption models: an investigation of alternative explanations. Am. J. Agric. Econ., 76, 535-546.
Shikur, H.Z., Legesse, B., Haji, J., Jaleta, M. (2020). Governance structures and incentives in the wheat value chain in Ethiopia. Afr. J. Agric. Res. Econ., 15(2), 157-176.

Williamson, O.E. (1985). The economic institutions of capitalism: Firms, markets, relational contracting. New York: Free Press.

Williamson, O.E. (1996). The mechanisms of governance. Oxford: Oxford University Press.

Williamson, O.E. (1999). Strategy research: governance and competence perspectives. Strat. Manag. J. 20(12), $1087-1108$.

Wilson, J. (1986). The political economy of contract farming. Rev. Radic. Pol. Econ., 18, 47-70.

Wimmer, B.S, Chezum, B. (2003). An empirical examination of quality certification in a 'lemons' market. Econ. Inq., 41(2), 279-291.

Wolf, S., Hueth, B., Ligon, E. (2001). Policing mechanisms in agricultural contracts. Rural Soc., 66(3), 359-381. 